\title{
Use of Data Mining Tools in the Fields of Tea Cultivation and Tea Industry of Assam
}

\author{
Sadiq Hussain \\ System Administrator \\ Examination Branch \\ Dibrugarh University
}

\author{
Nayeemuddin Ahmed \\ Assistant Professor \\ Centre for Computer Studies \\ Dibrugarh University
}

\begin{abstract}
Data mining has great potential in the fields of tea cultivation and tea industry of Assam for exploring the hidden patterns in the data sets of the domain. These patterns can be utilized for tea cultivation analysis. However, the available raw data are widely distributed, heterogeneous in nature, and voluminous. These data need to be collected in an organized form. This collected data can be then integrated to form an information system. Data mining technology provides a user-oriented approach to novel and hidden patterns in the data. Data mining and statistics both strive towards discovering patterns and structures in data. Statistics deals with heterogeneous numbers only, where data mining deals with heterogeneous fields.
\end{abstract}

\section{Keywords}

Data mining, Apriori Algorithm, Association Rule

\section{INTRODUCTION}

With the tremendous improvement in the speed of computer and the decreasing cost of data storage, huge volumes of data are created. However, data itself has no value. Only if data can be changed to information, it becomes useful. In order to generate meaningful information, or knowledge from database, the field of data mining was born. The data mining field is about two decade old. Early pioneers such as U. Fayyad, H. Mannila, G. Piatetsky-Shapiro, G. Djorgovski, W. Frawley, P. Smith, and others found that the traditional statistical techniques[9] were not adequate to handle the mass amount of data. They recognized the need of better, faster and cheaper ways to deal with the dramatic increase in the amount of data. Nowadays, besides the numerous number of databases created and accumulated in a dramatic speed, data is no longer restricted to numeric or character only especially in the industry and cultivation aspect. The advanced cultivation techniques, devices and database management systems enable the integration of the different types of high dimensional multimedia data (e.g. text, image, audio, and video) under the same umbrella. Establishing a methodology for knowledge discovery and management of large amounts of heterogeneous data has therefore become a main priority. In this paper we present our investigation results of the applications of the data mining in the tea cultivation aspect, which includes the area of biology, industry and economy.

\section{MATERIALS AND METHODS}

In this paper, we are creating tables containing information about all the years ( breaking down into months ) with the fields - rainfall, humidity, temperature and calculating amount produced by using association rule[6] and then apply the Apriori algorithm to see how the factors have effect on the production. The procedure of having the data marked as low,medium, high.

For making a field survey on Tea plants and Tea industry, we had visited a number of identified district of Assam in various tea gardens of Assam and Research organization such as PanitolaTea Estate of Tinsukia District,Chabua Tea Estate of Dibrugargh District ,Moran Tea Estate of Sibsagar District, Bargang Tea Estate of Sonitpur,Monabari T.E of Sonitpurand Dikom Tea Research Center.We personally interact with all the managers and co-workers of various tea gardens.I also personally interact with head of the Dikom Tea Research association(TRA) to collect data and important information required in accomplishing my task. In addition, we had inputs from local reports, communications and scientific publications from different areas of north-east India.

\section{RESULTS AND DISCUSSION}

In computer science and data mining, Apriori[3] is a classic algorithm for learning association rules. Apriori is designed to operate on databases containing transactions (for example, collections of items bought by customers, or details of a website frequentation). Other algorithms are designed for finding association rules in data having no transactions (Winepi and Minepi), or having no timestamps (DNA sequencing).

As is common in association rule mining[8], given a set of itemsets (for instance, sets of retail transactions, each listing individual items purchased), the algorithm attempts to find subsets which are common to at least a minimum number $\mathrm{C}$ of the itemsets. Apriori uses a "bottom up" approach, where frequent subsets are extended one item at a time (a step known as candidate generation), and groups of candidates are tested against the data. The algorithm terminates when no further successful extensions are found. 
Table I. Production Table based on Data Collected

\begin{tabular}{|l|l|l|l|l|l|}
\hline Month/ Year & $\mathbf{2 0 0 5}$ & $\mathbf{2 0 0 6}$ & $\mathbf{2 0 0 7}$ & $\mathbf{2 0 0 8}$ & $\mathbf{2 0 0 9}$ \\
\hline Jan & 0 & 0 & 0 & 0 & 0 \\
\hline Feb & 0 & 1599 & 1342 & 1185 & 3636 \\
\hline March & 151010 & 189124 & 262660 & 133154 & 36596 \\
\hline April & 353315 & 187321 & 273449 & 459444 & 350557 \\
\hline May & 400543 & 494598 & 418597 & 454582 & 413541 \\
\hline June & 541984 & 492081 & 605315 & 633638 & 614299 \\
\hline July & 848446 & 799747 & 848820 & 850948 & 775275 \\
\hline Aug & 936297 & 806514 & 816914 & 890857 & 961652 \\
\hline Sep & 770740 & 882183 & 937639 & 824813 & 876388 \\
\hline Oct & 861222 & 812251 & 832204 & 931347 & 925059 \\
\hline Nov & 463008 & 424444 & 475977 & 459067 & 524083 \\
\hline Dec & 127898 & 116789 & 106581 & 80184 & 122738 \\
\hline
\end{tabular}

\section{January Month}

$\mathrm{LT}=$ low temperature $\mathrm{LT}$ range $=9^{\circ}--25^{\circ} \mathrm{C}$

$\mathrm{LR}=$ low rainfall $\quad \mathrm{LR}$ range $=0-10 \mathrm{~cm}$

LH=low humidity $\quad$ LH range $=$ morning $(83-87 \%)$ and afternoon $(85-88 \%)$

Temperature width=16, Rainfall width $=10$, Humidity width $=5$ 


\begin{tabular}{|l|l|}
\hline TID & List of item IDs \\
\hline 2005 & LT,LR,LH \\
2006 & LT,LR,LH \\
2007 & LT,LR,LH \\
2008 & LT,LR,LH \\
2009 & LT,LR,LH \\
\hline
\end{tabular}

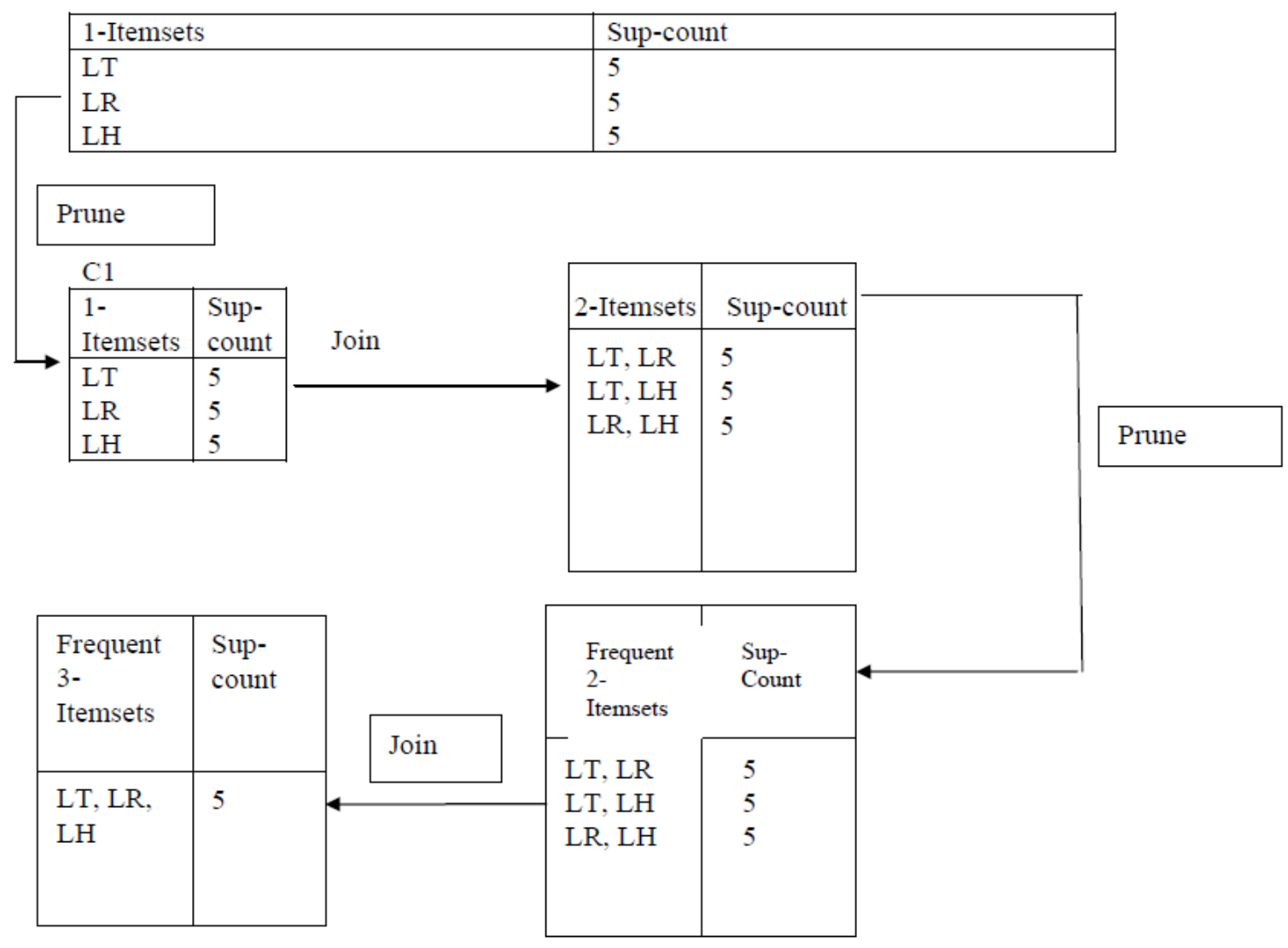

Applying Association Rule:

Temperature (X,'9---25')^ Rainfall (X,'0---10')^ Humidity (X,'83---87' \& X,'85---88)

Production (X,'0') 
February Month

$\mathrm{LT}=$ low temperature $\mathrm{LT}$ range $=9^{\circ}--25^{\circ} \mathrm{C}$

$\mathrm{LR}=$ low rainfall $\quad \mathrm{LR}$ range $=0-10 \mathrm{~cm}$

LH=low humidity $\quad$ LH range $=$ morning $(83-87 \%)$ and afternoon $(85-88 \%)$

$\mathrm{MT}=$ medium temperature $\mathrm{MT}$ range $=13^{\circ}--29^{\circ} \mathrm{C}$

Temperature width $=16$, Rainfall width $=10$, Humidity width $=5$

\begin{tabular}{|l|l|}
\hline TID & List of item IDs \\
\hline 2005 & MT,LR,LH \\
2006 & MT,LR,LH \\
2007 & MT,LR,LH \\
2008 & MT,LR,LH \\
2009 & MT,LR,LH \\
\hline
\end{tabular}

\begin{tabular}{|l|l|}
\hline 1-Itemsets & Sup-count \\
\hline MT & 5 \\
LR & 5 \\
LH & 5 \\
\hline
\end{tabular}

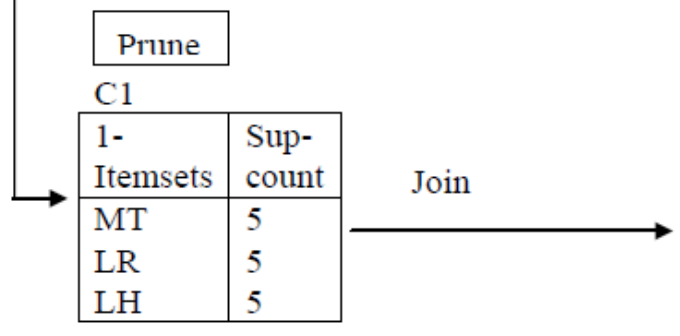

\begin{tabular}{|l|l|}
\hline $\begin{array}{l}\text { Frequent } \\
2-\end{array}$ & Sup-count \\
Itemsets & \\
\hline & \\
MT,LR & 5 \\
MT,LH & 5 \\
LR. LH & 5 \\
\hline
\end{tabular}

\begin{tabular}{|l|l|}
\hline $\begin{array}{l}\text { Frequent } \\
\text { 3-Itemsets }\end{array}$ & $\begin{array}{l}\text { Sup- } \\
\text { count }\end{array}$ \\
\hline MT, LR, LH & 5 \\
\hline
\end{tabular}

\begin{tabular}{|l|c|}
\hline $\begin{array}{l}\text { Frequent } \\
\text { 2-Itemsets }\end{array}$ & $\begin{array}{l}\text { Sup- } \\
\text { Count }\end{array}$ \\
\hline & \\
MT, LR & 5 \\
MT, LH & 5 \\
LR, LH & 5 \\
& \\
& \\
\hline
\end{tabular}

Applying Association Rule:

Temperature (X,'13---29')^ Rainfall (X,'0---10')^ Humidity (X,'83---87' \& X,'85---88') $\Longrightarrow$

Production (X,'1k---4k') where $\mathrm{k}=1000$ 
March Month

$\mathrm{LT}=$ low temperature $\mathrm{LT}$ range $=9^{\circ}--25^{\circ} \mathrm{C}$

$\mathrm{MT}=$ medium temperature $\mathrm{MT}$ range $=13^{\circ}--29^{\circ} \mathrm{C}$

$\mathrm{LR}=$ low rainfall $\mathrm{LR}$ range $=0-10 \mathrm{~cm}$

$\mathrm{MR}=$ medium rainfall $\quad \mathrm{MR}$ range $=10---20$

$\mathrm{LH}=$ low humidity $\quad \mathrm{LH}$ range $=\operatorname{morning}(83-87 \%)$ and afternoon $(85-88 \%)$

Temperature width $=16$, Rainfall width $=10$, Humidity width $=5$

\begin{tabular}{|l|l|}
\hline TID & List of item IDs \\
\hline 2005 & MT,MR,LH \\
2006 & MT,LR,LH \\
2007 & MT,LR,LH \\
2008 & MT,LR,LH \\
2009 & MT,LR,LH \\
\hline
\end{tabular}

\begin{tabular}{|l|l|}
\hline 1-Itemsets & Sup-count \\
\hline MT & 5 \\
MR & 1 \\
LR & 5 \\
LH & 5 \\
\hline
\end{tabular}
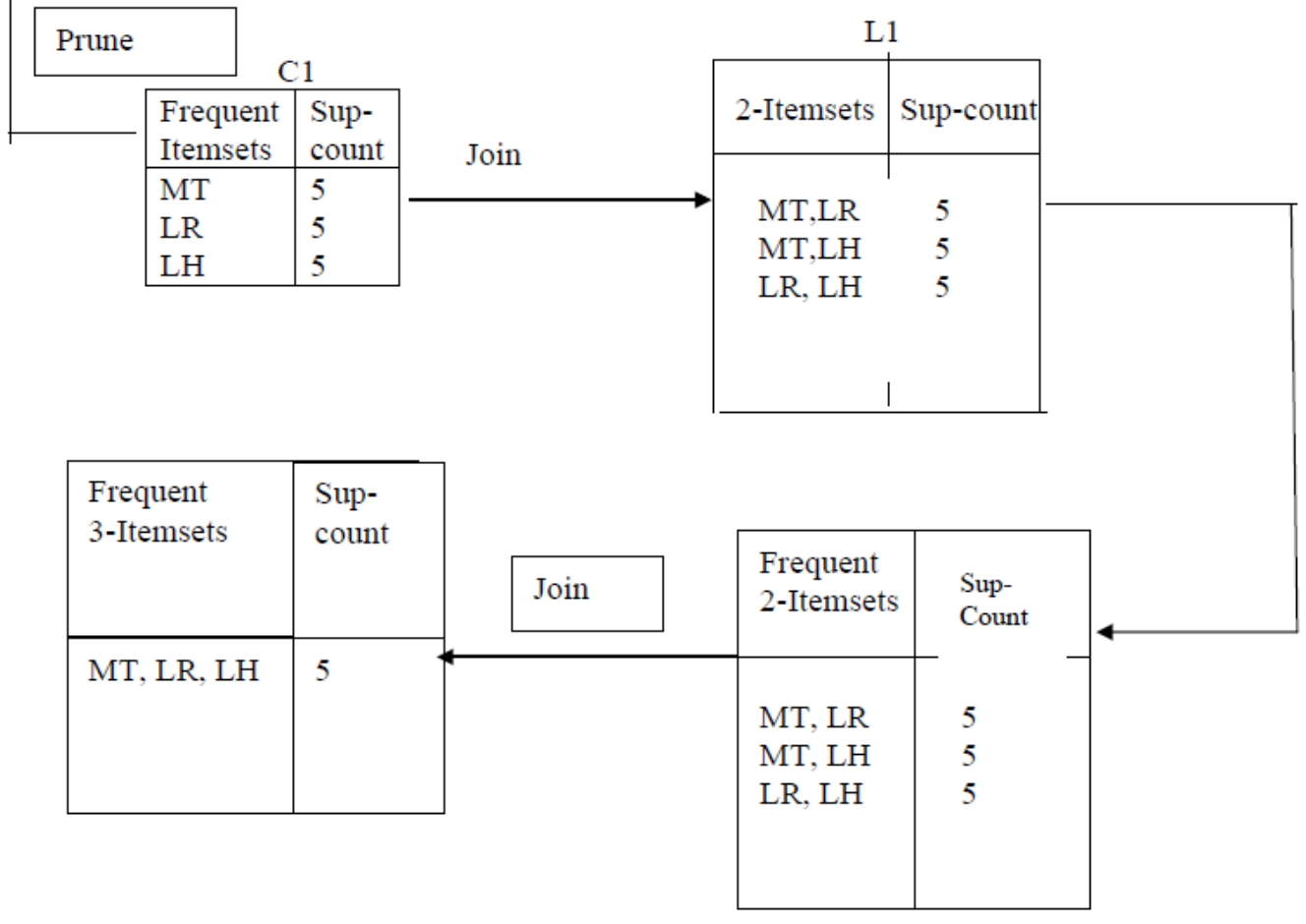

Prune

\section{Applying Association Rule:}

Temperature (X,'13---29') ^ Rainfall (X,'0---10')^ Humidity (X,'83---87' \& X,'85---88') $\square$

Production (X,'3k---270k') where $\mathrm{k}=1000$ 
April Month

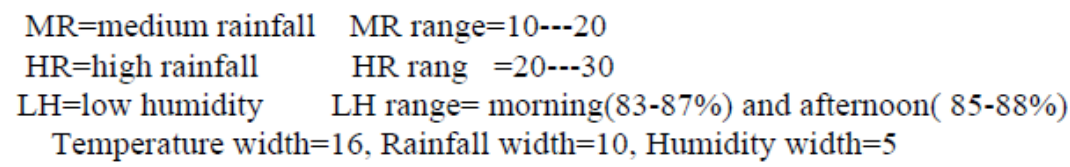

\begin{tabular}{|l|l|}
\hline TID & List of item IDs \\
\hline 2005 & MT,HR,LH \\
2006 & MT,MR,LH \\
2007 & MT,HR,LH \\
2008 & MT,MR,LH \\
2009 & MT,MR,LH \\
\hline
\end{tabular}

\begin{tabular}{|l|l|}
\hline 1-Itemsets & Sup-count \\
\hline MT & 5 \\
HR & 2 \\
MR & 3 \\
LH & 5 \\
\hline
\end{tabular}

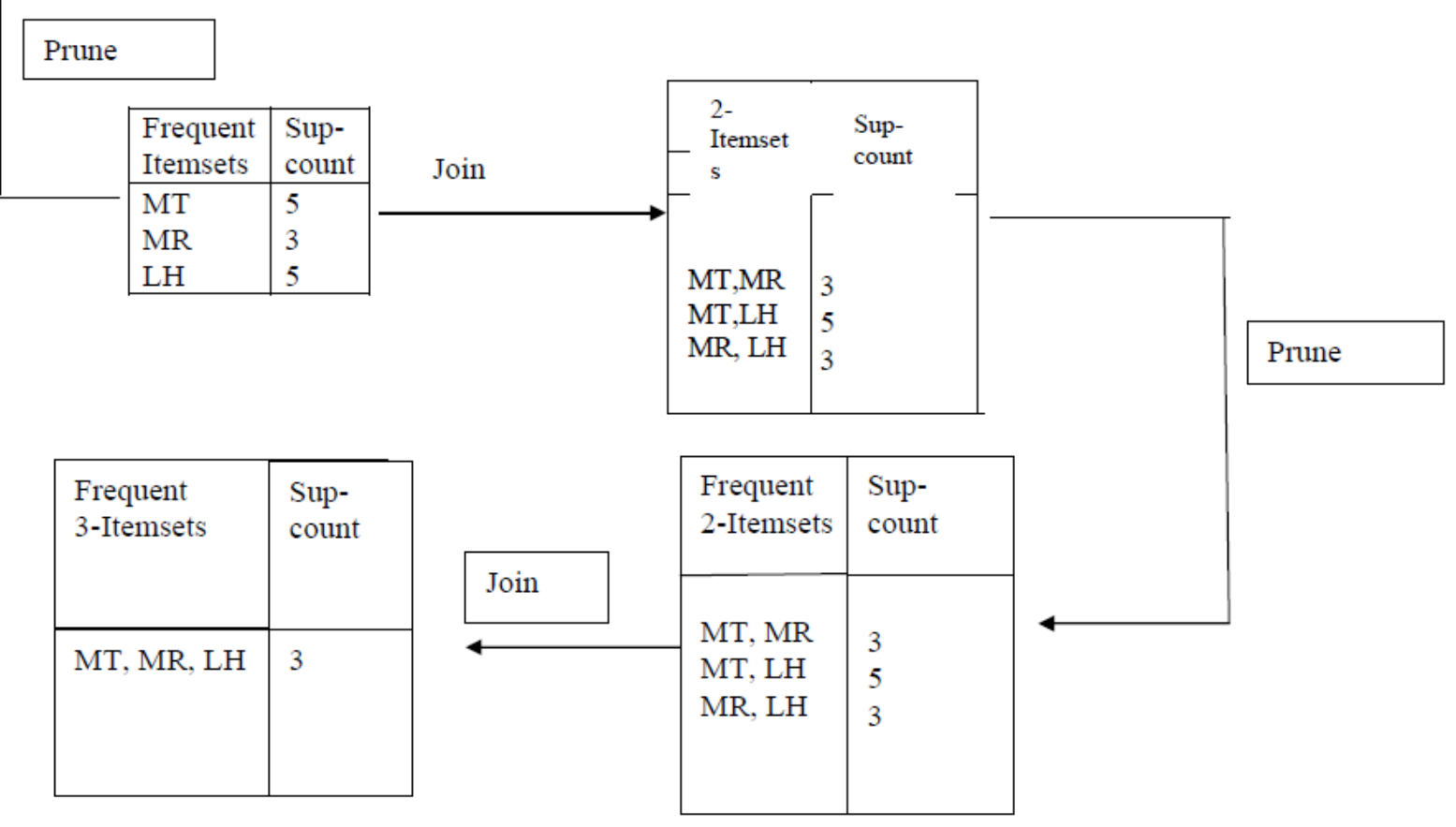

\section{Applying Association Rule:}

Temperature (X,'13---29')^ Rainfall (X,'10---20')^ Humidity (X,'83---87' \& X,'85---88') $\square$

Production (X,'271k---399k') where $\mathrm{k}=1000$ 
May Month

$\mathrm{HT}=$ high temperature $\mathrm{HT}$ range $=20^{\circ}--36^{\circ} \mathrm{C}$

$\mathrm{MR}=$ medium rainfall $\mathrm{MR}$ range $=10---20$

$\mathrm{HR}=$ high rainfall $\mathrm{HR}$ rang $=20---30$

$\mathrm{MH}=$ low humidity $\quad \mathrm{MH}$ range $=$ morning $(88-92 \%)$ and afternoon $(88-92 \%)$

Temperature width $=16$, Rainfall width $=10$, Humidity width $=5$

\begin{tabular}{|l|l|}
\hline TID & List of item IDs \\
\hline 2005 & MT,HR,LH \\
2006 & MT,MR,LH \\
2007 & MT,HR,LH \\
2008 & MT,MR,LH \\
2009 & MT,MR,LH \\
\hline
\end{tabular}

\begin{tabular}{|l|l|}
\hline 1-Itemsets & Sup-count \\
\hline HT & 5 \\
MR & 1 \\
MH & 5 \\
HR & 4 \\
\hline
\end{tabular}

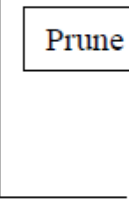

rune

\begin{tabular}{|l|l|l|l|l|}
\hline $\begin{array}{l}\text { Frequent } \\
\text { Itemsets }\end{array}$ & $\begin{array}{l}\text { Sup- } \\
\text { count }\end{array}$ \\
\hline HT & 5 \\
MH & 5 \\
HR & 4 & Join & $\begin{array}{l}2 \\
\text { Itemset } \\
\text { s }\end{array}$ & $\begin{array}{l}\text { Sup- } \\
\text { count }\end{array}$ \\
& & \\
HT, MH & 5 \\
HT, HR & 4 \\
MH, HR & 4 \\
\end{tabular}

\begin{tabular}{|c|c|c|c|c|}
\hline \multirow{3}{*}{$\begin{array}{l}\text { Frequent } \\
\text { 3-Itemsets }\end{array}$} & \multirow{3}{*}{$\begin{array}{l}\text { Sup- } \\
\text { count }\end{array}$} & \multirow{3}{*}{ Join } & \multirow{3}{*}{$\begin{array}{l}\text { Frequent } \\
\text { 2-Itemsets }\end{array}$} & \multirow{3}{*}{$\begin{array}{l}\text { Sup- } \\
\text { count }\end{array}$} \\
\hline & & & & \\
\hline & & & & \\
\hline HT, HR, MH & 4 & & \multirow{4}{*}{$\begin{array}{l}\mathrm{HT}, \mathrm{MH} \\
\mathrm{HT}, \mathrm{HR} \\
\mathrm{MH}, \mathrm{HR}\end{array}$} & \multirow{4}{*}{$\begin{array}{l}5 \\
4 \\
4\end{array}$} \\
\hline & & & & \\
\hline & & & & \\
\hline & & & & \\
\hline
\end{tabular}

Applying Association Rule:

Temperature $\left(\mathrm{X},{ }^{2} 20---36 '\right)^{\wedge}$ Rainfall $\left(\mathrm{X},{ }^{\prime 20---30 ') \wedge}\right.$ Humidity (X,'88---92' \& X,'88---92') $\Longrightarrow$

Production (X,'400k---499k')

where $\mathrm{k}=1000$ 
June Month

$\mathrm{HT}=$ high temperature $\mathrm{HT}$ range $=20^{\circ}--36^{\circ} \mathrm{C}$

$\mathrm{MR}=$ medium rainfall $\mathrm{MR}$ range $=10---20$

$\mathrm{HR}=$ high rainfall $\mathrm{HR}$ rang $=20---30$

$\mathrm{MH}=$ low humidity $\quad \mathrm{MH}$ range= morning $(88-92 \%)$ and afternoon $(88-92 \%)$

$\mathrm{HH}=$ high humidity $\mathrm{HH}$ range= morning $(93-97 \%)$ and afternoon $(90-94 \%)$

Temperature width $=16$, Rainfall width $=10$, Humidity width $=5$

\begin{tabular}{|l|l|}
\hline TID & List of item IDs \\
\hline 2005 & HT,MR,HH \\
2006 & HT,HR,HH \\
2007 & HT,HR,MH \\
2008 & HT,HR,HH \\
2009 & HT,HR,HH \\
\hline
\end{tabular}

\begin{tabular}{|l|l|}
\hline 1-Itemsets & Sup-count \\
\hline HT & 5 \\
MR & 1 \\
MH & 1 \\
HH & 4 \\
HR & 4 \\
\hline
\end{tabular}

\section{Prune}

\begin{tabular}{|l|l|}
$\begin{array}{l}\text { Frequent } \\
\text { Itemsets }\end{array}$ & $\begin{array}{l}\text { Sup- } \\
\text { count }\end{array}$ \\
\hline $\mathrm{HT}$ & 5 \\
$\mathrm{HH}$ & 4 \\
$\mathrm{HR}$ & 4 \\
\hline
\end{tabular}

\begin{tabular}{l|l|}
\begin{tabular}{l|l}
$2-$ \\
Itemsets
\end{tabular} & $\begin{array}{l}\text { Sup- } \\
\text { count }\end{array}$ \\
& \\
HT, HH & 4 \\
HT, HR & 4 \\
HH, HR & 4 \\
& \\
\hline
\end{tabular}
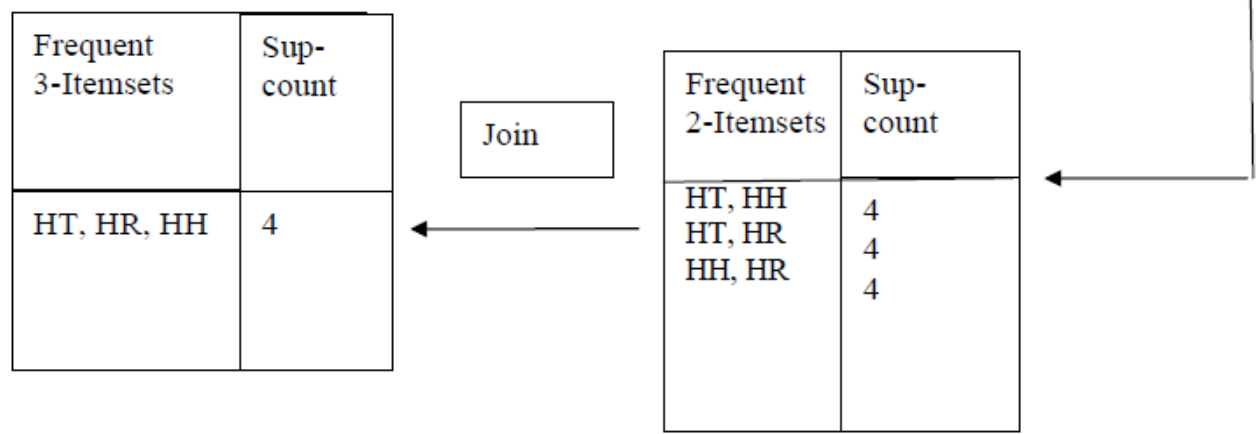

\section{Applying Association Rule:}

Temperature (X,'20---36')^ Rainfall (X,'20---30')^ Humidity (X,'93---97' \& X,'90---94')

Production (X,'500k---634k')

where $\mathrm{k}=1000$ 
July Month

$\mathrm{HR}=$ high rainfall $\mathrm{HR}$ rang $=20---30$

$\mathrm{HH}=$ high humidity $\quad \mathrm{HH}$ range= morning $(93-97 \%)$ and afternoon $(90-94 \%)$

Temperature width $=16$, Rainfall width $=10$, Humidity width $=5$

\begin{tabular}{|l|l|}
\hline TID & List of item IDs \\
\hline 2005 & HT,HR,HH \\
2006 & HT,HR,HH \\
2007 & HT,HR,HH \\
2008 & HT,HR,HH \\
2009 & HT,HR,HH \\
\hline
\end{tabular}

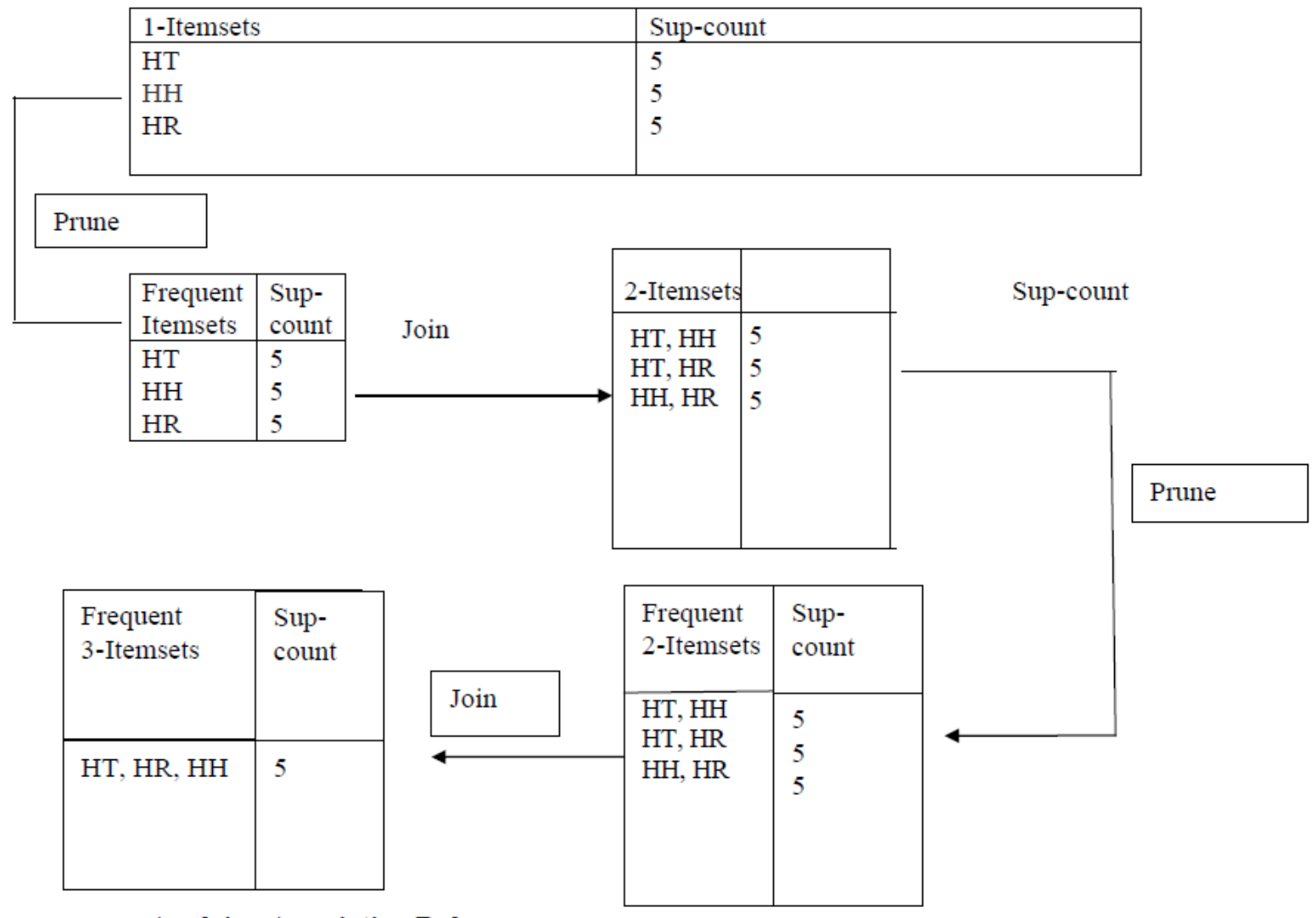

Applying Association Rule:

Temperature (X,'20---36')^ Rainfall (X,'20---30')^ Humidity (X,'93---97' \& X,'90---94')

Production (X,'635k---851k') where $\mathrm{k}=1000$ 
August Month

$\mathrm{HT}=$ high temperature $\mathrm{HT}$ range $=20^{\circ}--36^{\circ} \mathrm{C}$

$\mathrm{LR}=$ low rainfall $\mathrm{LR}$ range $=0--10$

$\mathrm{HR}=$ high rainfall $\quad \mathrm{HR}$ range $=20---30$

$\mathrm{HH}=$ high humidity $\quad \mathrm{HH}$ range= morning $(93-97 \%)$ and afternoon $(90-94 \%)$

Temperature width $=16$, Rainfall width $=10$, Humidity width $=5$

\begin{tabular}{|l|l|}
\hline TID & List of item Ids \\
\hline 2005 & HT,HR,HH \\
2006 & HT,LR,HH \\
2007 & HT,HR,HH \\
2008 & HT,HR,HH \\
2009 & HT,HR,HH \\
\hline
\end{tabular}

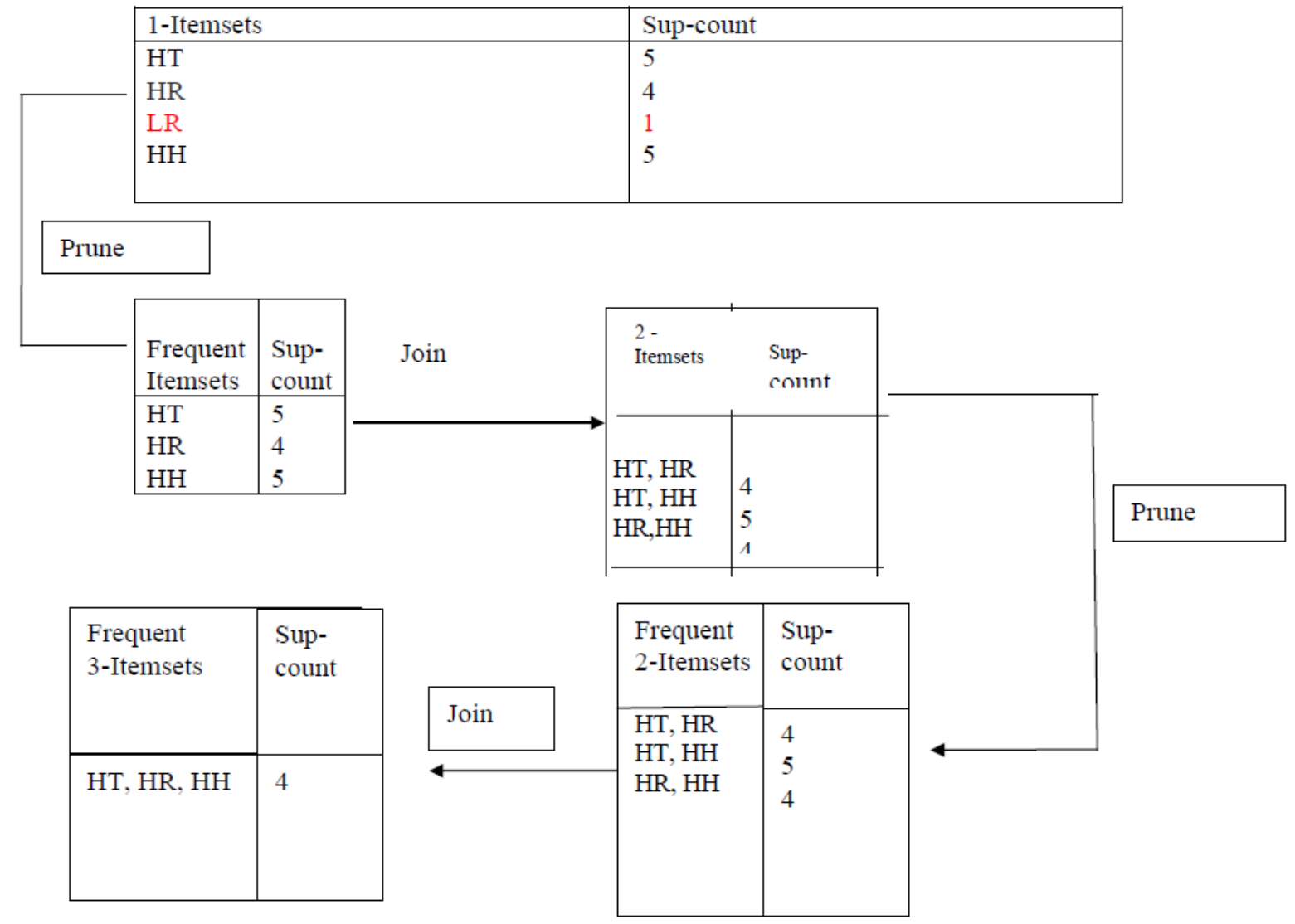

Applying Association Rule:

Temperature $\left(\mathrm{X},{ }^{\prime} 20---36\right)^{\wedge}$ Rainfall $\left(\mathrm{X},{ }^{\prime} 20---30\right.$ ') ^ Humidity (X,'93---97' \& X,'90---94')

Production (X,'800k---962k')

where $\mathrm{k}=1000$ 
September Month

$\mathrm{HT}=$ high temperature $\mathrm{HT}$ range $=20^{\circ}--36^{\circ} \mathrm{C}$

$\mathrm{LR}=$ low rainfall $\quad \mathrm{LR}$ range $=0-10$

$\mathrm{HR}=$ high rainfall $\quad \mathrm{HR}$ range $=20--30$

$M R=$ medium rainfall $M R$ range $=10--20$

$\mathrm{HH}=$ high humidity $\quad \mathrm{HH}$ range= morning $(93-97 \%)$ and afternoon $(90-94 \%)$

Temperature width $=16$, Rainfall width $=10$. Humidity width $=5$

\begin{tabular}{|l|l|}
\hline TID & List of item Ids \\
\hline 2005 & HT,LR,HH \\
2006 & HT,LR,HH \\
2007 & HT,HR,HH \\
2008 & HT,LR,HH \\
2009 & HT,MR,HH \\
\hline
\end{tabular}

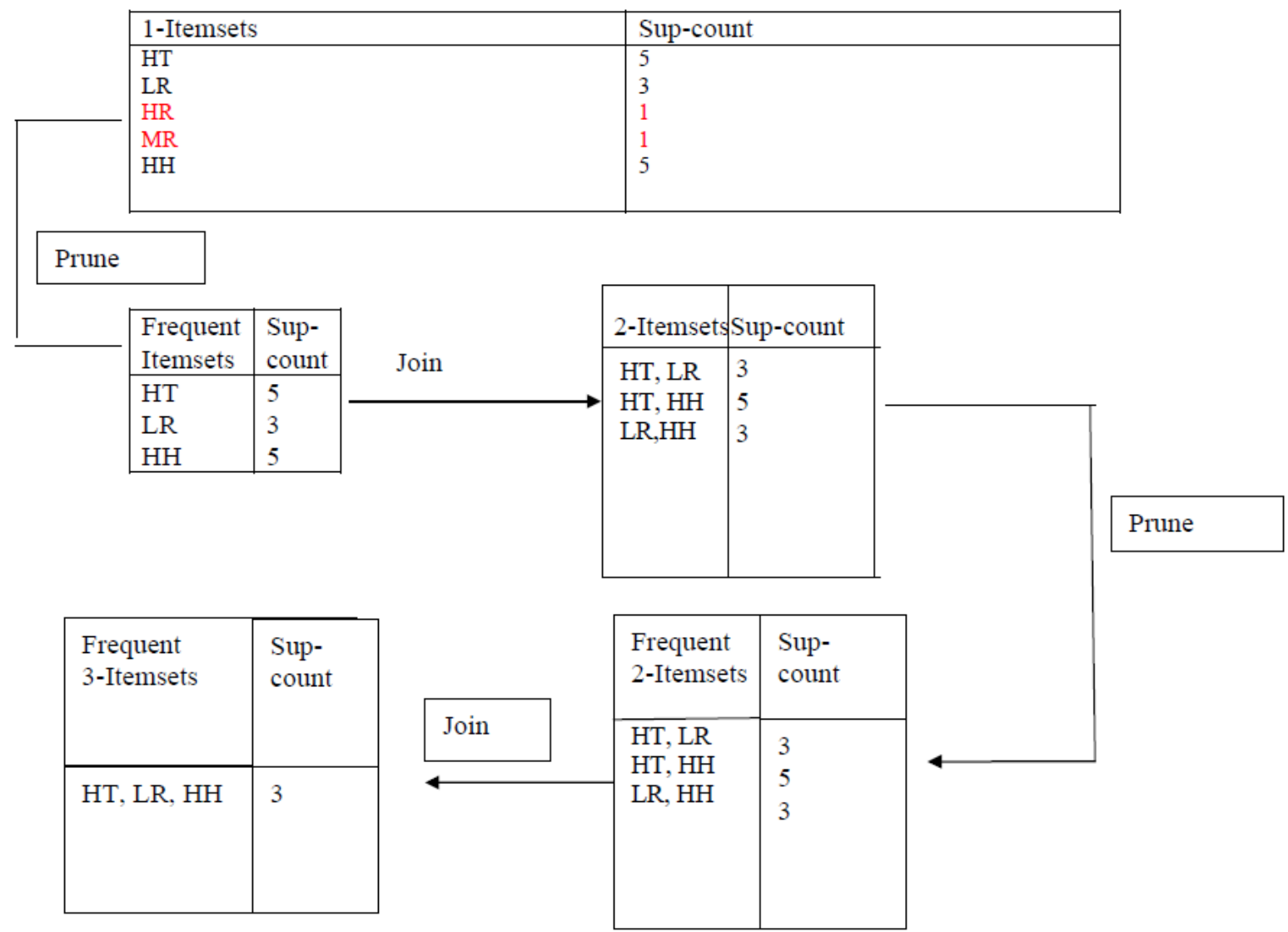

Temperature (X,'20---36')^ Rainfall (X,'0---10')^ Humidity (X,'93---97' \& X,'90---94') Production (X,'770k---938k') where $\mathrm{k}=1000$ 
October month

$\mathrm{HT}=$ high temperature $\mathrm{HT}$ range $=20^{\circ}--36^{\circ} \mathrm{C}$

$\mathrm{LR}=$ low rainfall $\quad \mathrm{LR}$ range $=0---10$

$M R=$ medium rainfall $\mathrm{MR}$ range $=10--20$

$\mathrm{MH}=$ medium humidity $\quad \mathrm{MH}$ range $=\operatorname{morning}(88-92 \%)$ and afternoon $(88-92 \%)$

Temperature width $=16$, Rainfall width $=10$, Humidity width $=5$

\begin{tabular}{|l|l|}
\hline & List of item IDs \\
\hline 2005 & HT,MR,MH \\
2006 & HT,LR,MH \\
2007 & HT,LR,MH \\
2008 & HT,LR,MH \\
2009 & HT,MR,MH \\
\hline
\end{tabular}

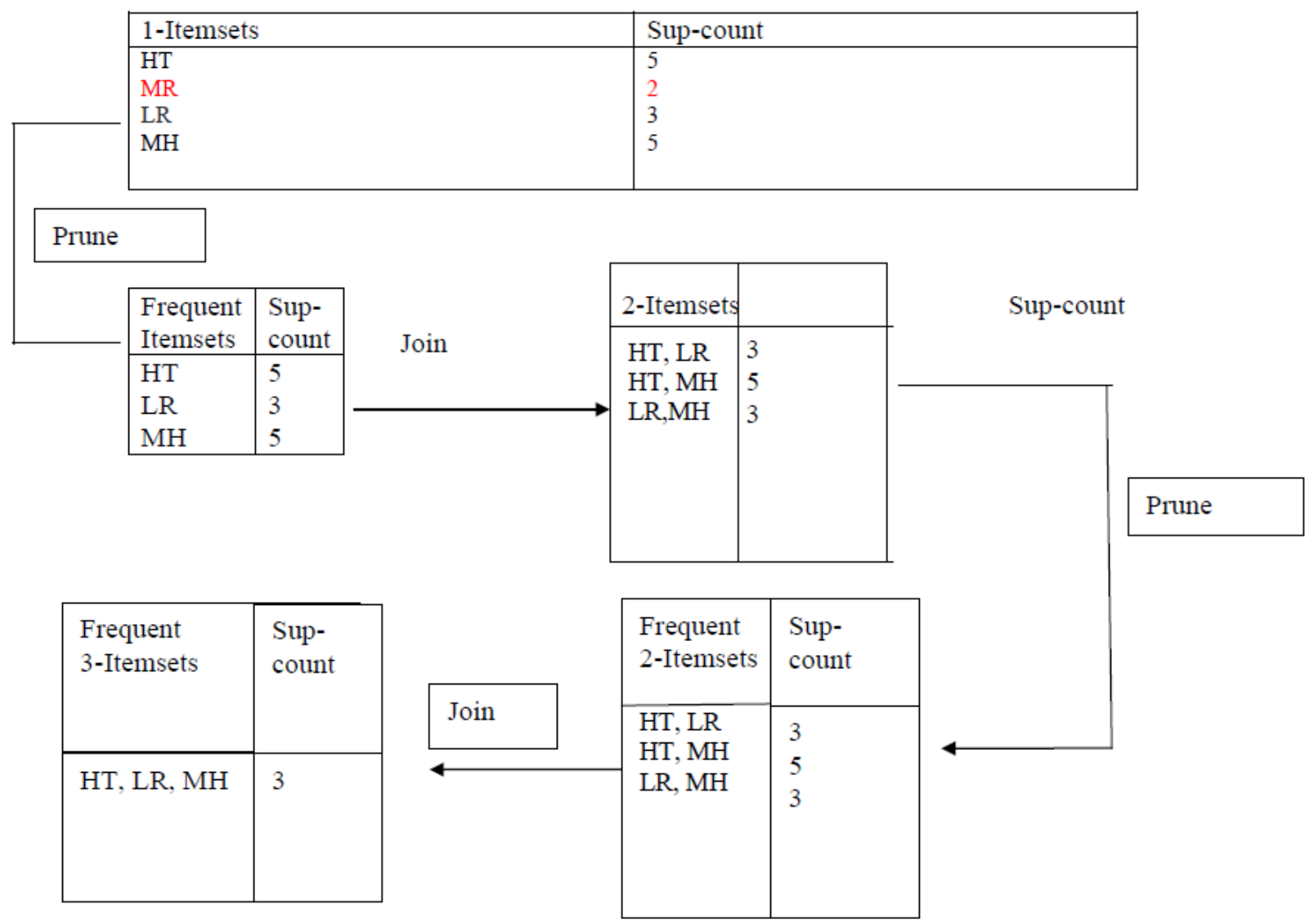

Applying Association Rule:

Temperature (X,'20---36')^ Rainfall (X,'0---10')^ Humidity (X,'88---92' \& X,'88---92') $\Longrightarrow$

Production (X,'812k---925k') where k=1000 
November Month

$\mathrm{MT}=$ medium temperature $\mathrm{MT}$ range $=13^{\circ}--29^{\circ} \mathrm{C}$

$\mathrm{LR}=$ low rainfall $\quad \mathrm{LR}$ range $=0-10$

$\mathrm{MH}=$ medium humidity $\quad \mathrm{MH}$ range $=$ morning $(88-92 \%)$ and afternoon $(88-92 \%)$

Temperature width $=16$, Rainfall width $=10$, Humidity width $=5$

\begin{tabular}{|l|l|}
\hline TID & List of item IDs \\
\hline 2005 & MT,LR,MH \\
2006 & MT,LR,MH \\
2007 & MT,LR,MH \\
2008 & MT,LR,MH \\
2009 & MT,LR,MH \\
\hline
\end{tabular}

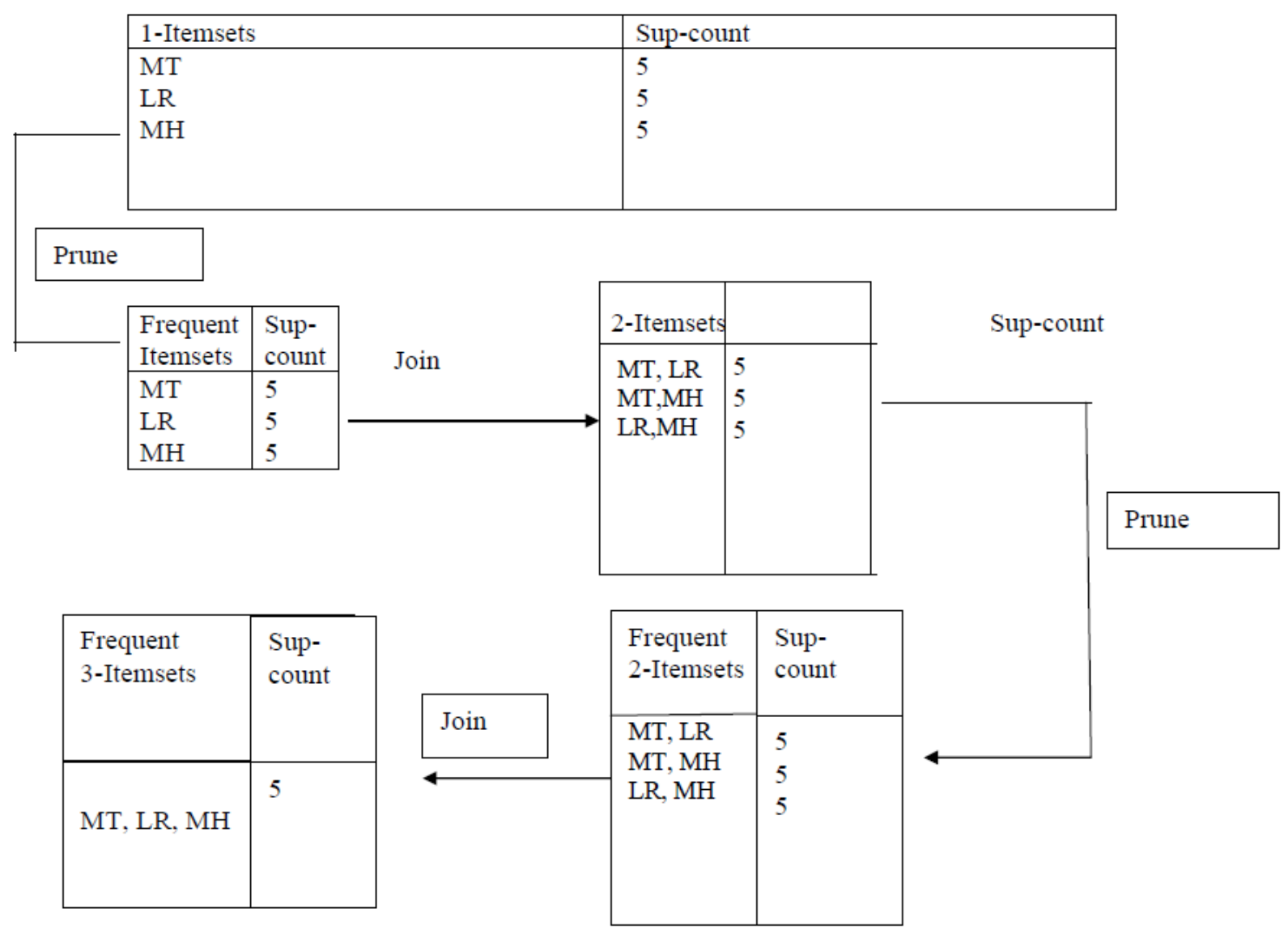

Applying Association Rule:

Temperature (X,'13---29')^ Rainfall (X,'0---10') ^ Humidity (X,'88---92' \& X,'88---92')

Production (X,'424k---524k') where $\mathrm{k}=1000$ 
December Month

$\mathrm{LT}=$ Low temperature $\mathrm{LT}$ range $=9^{\circ}--25^{\circ} \mathrm{C}$

$\mathrm{LR}=$ low rainfall LR range $=0-10$

LH=low humidity $\quad$ LH range $=$ morning $(83-87 \%)$ and afternoon $(85-88 \%)$ Temperature width $=16$, Rainfall width $=10$, Humidity width $=5$

\begin{tabular}{|l|l|}
\hline TID & List of item IDs \\
\hline 2005 & LT,LR,LH \\
2006 & LT,LR,LH \\
2007 & LT,LR,LH \\
2008 & LT,LR,LH \\
2009 & LT,LR,LH \\
\hline
\end{tabular}

\begin{tabular}{|l|l|}
\hline 1 -Itemsets & Sup-count \\
\hline LT & 5 \\
LR & 5 \\
LH & 5 \\
& \\
\hline
\end{tabular}
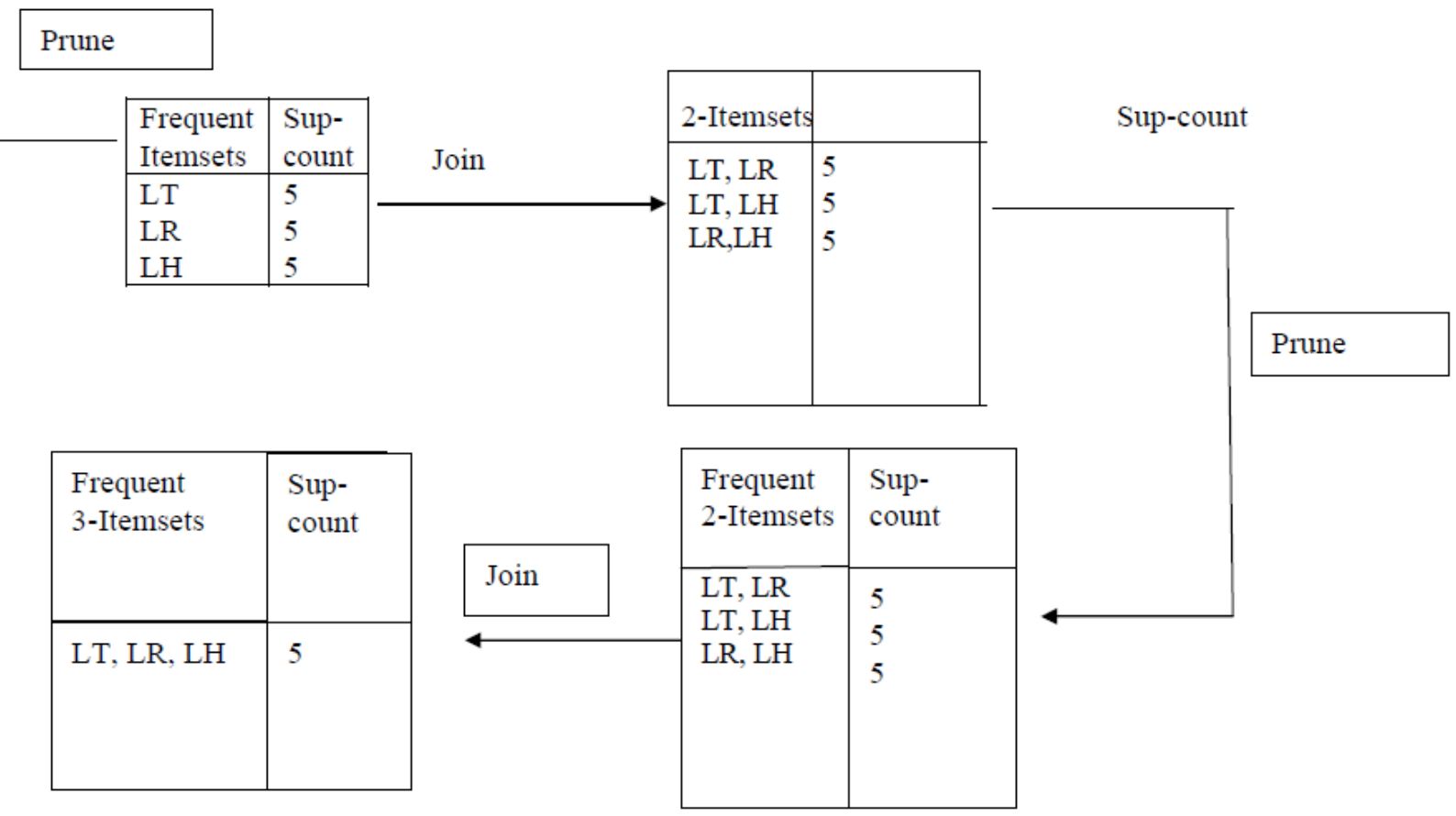

\section{Applying Association Rule:}

Temperature $\left.\left(\mathrm{X},{ }^{\prime} 9-25---36\right)^{\prime}\right)^{\wedge}$ Rainfall $\left(\mathrm{X},{ }^{\prime} 0---10^{\prime}\right) \wedge$ Humidity (X,'83---87' \& X,'85---88')

Production (X,'80k---127k') where $\mathrm{k}=1000$ 


\section{CONCLUSION}

The purpose of this paper was to obtain the information about production of Tea and explore which factors impacted on the production of Tea. Our results show that most of the tea productions have dependent rainfall, humidity, temperature, men power used, sunshine hours and type of seed used. From the factors we have seen that production is low in month of January, February and in the month of November and December. From the collected data it has been observed that at that time temperature is low $\left(9^{\circ}-25^{\circ} \mathrm{C}\right)$, rainfall is also less $(0-10 \mathrm{~cm})$ and humidity is also low (morning (83-87\%) and afternoon (85$88 \%)$ ). Therefore production is comparatively low. After applying association rule we can find that productions nill.In the month of February temperature is increases from low to medium $\left(13^{\circ}--29^{\circ} \mathrm{C}\right)$. Tea is produced very low amounts. In the month of march temperature is medium $\left(13^{\circ}--29^{\circ} \mathrm{C}\right)$ and rainfall is medium $(10-20 \mathrm{~cm})$ and it gradually increases production. In the month of December temperature is low $\left(9^{\circ}-25^{\circ} \mathrm{C}\right)$, rainfall is also less $(0$ $10 \mathrm{~cm})$ and humidity is also low (morning (83-87\%) and afternoon ( $85-88 \%)$ ),therefore production is also low. In the .month of April temperature is medium $\left(13^{\circ}--29^{\circ} \mathrm{C}\right)$, rainfall is also medium $(10-20 \mathrm{~cm})$ but humidity is low. Here the production is comparatively more then march. In the month of May temperature is high $\left(20^{\circ}--36^{\circ} \mathrm{C}\right)$,rainfall is also high $(20-30 \mathrm{~cm})$ but the humidity is medium morning $(88-92 \%)$ and afternoon ( $88-92 \%)$. In this month the production is again increased.

In the month of June, July and August temperature is $\operatorname{high}\left(20^{\circ}-36^{\circ} \mathrm{C}\right)$,rainfall is high $(20-30 \mathrm{~cm})$ and humidity is also high morning (93-97\%) and afternoon ( 90-94\%) ).Production in these months is maximum. Again in the data if we see in the month September temperature is $\operatorname{high}\left(20^{\circ}--36^{\circ} \mathrm{C}\right)$,rainfall is $\operatorname{low}(0-10 \mathrm{~cm})$ and humidity is also high morning (93-97\%) and afternoon ( 90-94\%) ).Therefore production is slightly decreased. October temperature is high $\left(20^{\circ}--36^{\circ} \mathrm{C}\right)$, rainfall is low $(0-10 \mathrm{~cm})$ and humidity is medium morning (88-92\%) and afternoon ( 88$92 \%$ ), therefore production is further decreased. In November temperature is medium $\left(13^{\circ}--29^{\circ} \mathrm{C}\right)$, rainfall is low $(0-10 \mathrm{~cm})$ and the humidity is also medium morning (88$92 \%$ ) and afternoon ( 88-92\%) From the statistical studies it is also cleared the same. From this study we can conclude that production of Tea is high in generally at high temperature, high rainfall and high humidity. But there are lots of other factors such as no of shade tree in cultivation, drain system, day length, tea pest control ,manuring,plucking and type of seeds used in the cultivation.

The correlation and association[7] amongst the factors are found after the analysis the knowledge be can used in decision making purpose for part of the organization which are directly or indirectly associated on the production of a Tea Garden.

The well use of the data mining tools in the tea cultivation and tea industry should bring revolutionary impact to the field. The study of tea cultivation processes is heavily based on the identification of understandable patterns which are present in the data. These patterns may be used for study factors affecting tea production. Data mining is at the care of the pattern recognition[1] process. Biologist and computing professionals should collaborate so that the two fields can contribute to each other. The challenge is for each to widen its focus to attain harmonious and productive collaboration to develop the best practices.

\section{ACKNOWLEDGEMENT}

The well use of the data mining tools[2] in the tea cultivation and tea industry should bring revolutionary impact to the field. The study of tea cultivation processes is heavily based on the identification of understandable patterns [4] which are present in the data. These patterns may be used for study factors affecting tea production. Data mining is at the care of the pattern recognition[1] process. Biologist and computing professionals should collaborate so that the two fields can contribute to each other. The challenge is for each to widen its focus to attain harmonious and productive collaboration to develop the best practices.

\section{REFERENCES}

[1] J. T. Tou and R. C. Gonzalez, "Pattern recognition principles," Addison-Wesley, London, 1974.

[2] K. J. Cios, W. Pedrycz, R. W. Swiniarski, and L. A. Kurgan, "Data mining: A knowledge discovery approach," Springer, New York, 2007.

[3] Rakesh Agrawal and Ramakrishnan Srikant. Fast algorithms for mining association rules in large databases. Proceedings of the 20th International Conference on Very Large Data Bases, VLDB, pages 487-499, Santiago, Chile, September 1994

[4] R. O. Duda, P. E. Hart, and D. G. Stork, "Pattern classification,"Wiley,2001.

[5] T. Hastie, R. Tibshirani, and J. Friedman, "The elements of statistical learning: Data mining, inference, and prediction," Springer, New York, 2001.

[6] Aggarwal Charu and Yu Philip.Mining large itemsets for association rules.Bulletin Of the IEEE Computer Society Technical Committee on Data Engineering,21,no.1,March 1998

[7] Toivonen H.,Klemettinen M.,Ronkainen P.,Hatonen K and Mannila H."Pruning and grouping discovered association rules".Workshop on Statistical Machine Learning and Knowlege Discovery in Databases.1995

[8] Arun K Pujari "Data Mining Techniques"Universities Press,Pages 69-109,February 2001

[9] Alex Beyson and Steve Smith , "Data Warehousing,Data Mining and OLAP” 2004 